Artigo

\title{
Multiculturalismo e Direitos: uma abordagem conceitual
}

\author{
Multiculturalism and Rights: \\ a conceptual approach
}

\begin{abstract}
Multiculturalismo y derechos: una aproximación conceptual
\end{abstract}

Multiculturalisme et Droits: une approche conceptuelle

\footnotetext{
${ }^{1}$ Graduada e mestre em Filosofia, doutora em Psicologia Escolar e do Desenvolvimento Humano e Livre docência em Filosofia pela Universidade de São Paulo, São Paulo, SP, Brasil. Atualmente é pesquisadora do Grupo de Estudos e Pesquisas das Políticas Públicas para a Inclusão Social e é docente do curso de Gestão de Políticas Públicas, dos Programas de Pós-Graduação em Direitos Humanos e de PósGraduação Humanidades, Direitos e Outras Legitimidades da Universidade de São Paulo, São Paulo, SP, Brasil.

E-mail: gislene@usp.br
} 
Resumo

\section{Abstract}

Resumen

A discussão sobre multiculturalismo e sobre políticas públicas multiculturais tem sido objeto de controvérsias e de grande divergência conceitual. 0 presente texto atualiza o debate acerca do multiculturalismo, aponta as diferenças entre países multiculturais e países que, mesmo sendo multiculturais, não admitem políticas focalizadas no multiculturalismo. Discuto aqui alguns conceitos e ideias que podem ajudar a compreender diferentes aspectos do que se entende por multiculturalismo a partir das teorias da justiça, bem como as diferentes formas do tratamento normativo para as demandas dos grupos sociais nas sociedades contemporâneas.

Palavras-Chave: Teorias da Justiça; Normas; Valores; Políticas Públicas; Igualdade.

The discussion about multiculturalism and multicultural public policies has been the object of controversies and great conceptual divergence. The present text updates the debate about multiculturalism, points out the differences between multicultural countries and countries that, even being multicultural, do not admit policies focused on multiculturalism. I discuss here some concepts and ideas that can help to understand different aspects of what is understood by multiculturalism from the theories of justice, as well as the different forms of normative treatment to the demands of social groups in contemporary societies.

Keywords: Theories of Justice; Norms; Values; Public Policies; Equality.

La discusión sobre el multiculturalismo y las políticas públicas multiculturales ha sido objeto de controversias y grandes divergencias conceptuales. El presente texto actualiza el debate sobre el multiculturalismo, señala las diferencias entre los países multiculturales y los que, aun siendo multiculturales, no admiten políticas centradas en el multiculturalismo. Discuto aquí algunos conceptos e ideas que pueden ayudar a entender diferentes aspectos de lo que se entiende por multiculturalismo desde las teorías de la justicia, así como las diferentes formas de tratamiento normativo a las demandas de los grupos sociales en las sociedades contemporáneas.

Palabras Clave: Teorías de la Justicia; Normas; Valores; Políticas Públicas; Igualdad. 
Résumé Le débat sur le multiculturalisme et les politiques publiques multiculturelles a fait l'objet de controverses et de grandes divergences conceptuelles. Le présent texte actualise le débat sur le multiculturalisme, souligne les différences entre les pays multiculturels et les pays qui, bien qu'étant multiculturels, n'admettent pas de politiques axées sur le multiculturalisme. J'aborde ici quelques concepts et idées qui peuvent aider à comprendre les différents aspects de ce que l'on entend par multiculturalisme à partir des théories de la justice, ainsi que les différentes formes de traitement normatif aux demandes des groupes sociaux dans les sociétés contemporaines.

Mots-Clés: Théories de la Justice; Normes; Valeurs; Politiques Publiques; Égalité. 
A discussão sobre multiculturalismo e sobre políticas públicas multiculturais tem sido objeto de controvérsias e de grande divergência conceitual. 0 que seria o multiculturalismo? Haveria somente uma forma de multiculturalismo? Podemos encontrar diferenças entre países multiculturais (como o Brasil) e países que, mesmo sendo multiculturais, não admitem políticas focalizadas no multiculturalismo (como a França)? Ou, ainda, há diferença entre esses países e aqueles que, efetivamente, possuem uma constituição multicultural (como o Canadá)? Diversidade cultural é igual a multiculturalismo? 0 que está implicado na implementação de políticas públicas multiculturais e quem teria direito a elas? Nesse texto, busco discutir alguns conceitos e ideias que podem ajudar a responder a essas perguntas.

Contextualizando a discussão sobre o multiculturalismo no seio das teorias da justiça, proponho uma reflexão sobre os contornos do multiculturalismo, sobre as políticas públicas multiculturais e as diferentes formas do tratamento normativo para as demandas dos grupos sociais nas sociedades contemporâneas.

\section{Teorias Normativas}

No âmbito das teorias políticas contemporâneas, podemos identificar algumas tendências gerais entre as quais se localiza o multiculturalismo. Apenas pretendo esquematizar as linhas gerais para que se entenda onde (esse último "ismo") se encontra.

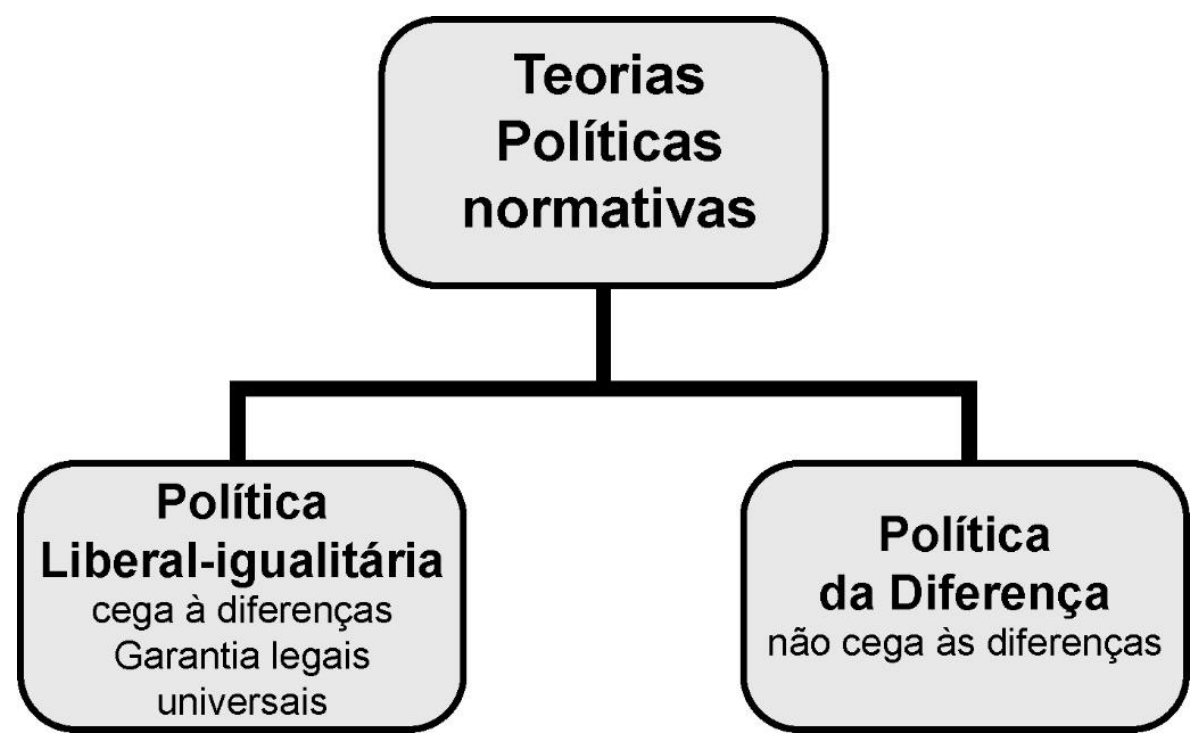

Figura 1 - Teorias políticas normativas I 
As tendências normativas, em geral, podem ser organizadas em torno das políticas liberaligualitárias que, se diz, são cegas às diferenças e buscam a construção de direitos a partir de parâmetros universais; e das políticas de diferença, que associam a demanda pela igualdade à observação da diversidade/diferenças existentes no seio das sociedades, de modo a considerálas na definição dos parâmetros para a justiça.

As políticas de diferença se dividiriam entre políticas da diferença cultural e políticas da diferença posicional/estrutural. 0 multiculturalismo, para alguns, diria respeito à diferença cultural (e não estrutural). Para outros, contemplaria tanto os aspectos culturais quanto os estruturais, ou seja, a cultura somada a um certo princípio de equidade.

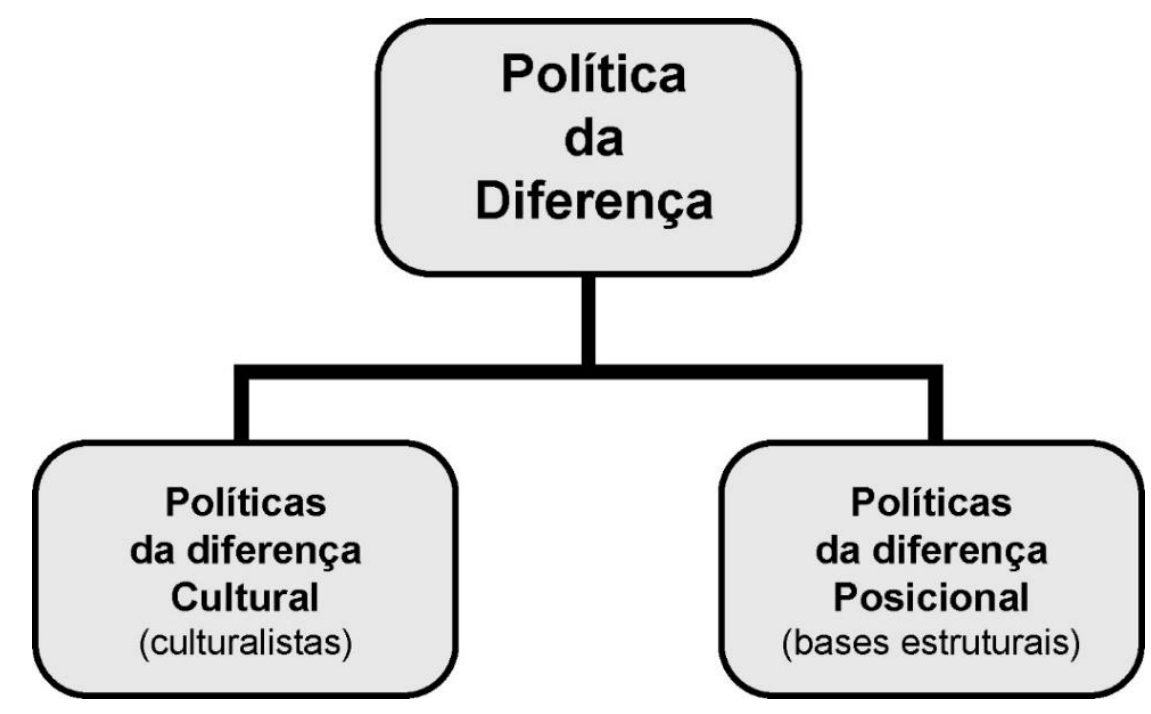

Figura 2 - Teorias políticas normativas II

\section{ACircunstâncias do Multiculturalismo}

Stuart Hall (2003) chama a atenção para o fato de que mesmo a definição do que seja o multiculturalismo é complexa e está longe de ser um consenso. Inicia sua avaliação sobre as aporias do multiculturalismo pela própria definição do termo multicultural e do termo multiculturalismo. 0 primeiro denota as características sociais e de governabilidades presentes em quaisquer sociedades nas quais diferentes comunidades, cada qual com uma cultura específica e uma identidade própria, tenta conviver com outras comunidades e culturas. Já o segundo termo nos conduz a pensar em estratégias políticas e ideologias. 
Hall considera ainda que, assim como há diferentes sociedades multiculturais, há também diferentes multiculturalismos: o conservador, o liberal, o pluralista, o comercial, o corporativo, o crítico, cada qual sendo questionado por seus opositores. No entanto, todos eles partiriam da pressuposição de que o multiculturalismo é uma política de reconhecimento das diferenças (Taylor, 2000). Também se pode admitir que embora a existência de sociedades multiculturais seja um fato antigo, uma política para o tratamento da diversidade é algo recente e que surge em oposição ao perfil homogeneizante dos estados-nações e das heranças colônias (cf. Hobsbawn,1999; Hall,2003).

Entretanto, tendo-se em vista as formas que o multiculturalismo pode assumir, essa política de reconhecimento também pode variar da aceitação da contribuição que os diferentes grupos culturais deram ao mainstream até a concessão de direitos e poderes equitativos a esses diferentes grupos socioculturais. Se não há uma única forma de multiculturalismo, também não haverá uma única forma de reconhecimento da diversidade e das diferenças.

Já Paul Kelly pergunta: O que significa o multiculturalismo? E responde que podemos considerar a existência de "circunstâncias do multiculturalismo" (circumstances of multiculturalism). As "circunstâncias do multiculturalismo" ocorreriam pela soma de duas variáveis: 1- o pluralismo, no sentido de entrelaçamento de minorias nacionais, indigenas (first nations), culturas étnicas e religiosas decorrentes da migração; e, 2- os problemas de discriminação, desvantagens, racismos, enfrentados por essas minorias, e que devem ser discutidos, tratados, resolvidos por meio de políticas públicas.

Os teóricos do multiculturalsimo objetivam responder a esses problemas. Interessante notar que eles não se referem às discriminações e racismos sofridos pelos negros em seus estados nacionais (ou países de cidadania). São considerados os problemas associados a migração e as questões vinculados aos estados poliétnicos, mas não os decorrentes do apartheid e das políticas de segregação motivadas pelo racismo (quer nos EUA, África do Sul ou em qualquer outro local).

Se considerarmos somente as "circunstâncias do multiculturalismo", ele pode ser entendido como a coexistência de várias culturas na mesma esfera pública. Contudo, não é essa a compreensão recorrente. 0 problema se coloca no momento em que se afirma que as "circunstâncias do multiculturalismo" desafiam as teorias tradicionais e as ideologias tradicionais a encontrarem alternativas para acomodar a elas mesmas às novas circunstâncias sociais (pluralismo, diversidade cultural, migração, diversidade religiosa, indígenas).

Kelly considera:

For some, the 'circumstances of multiculturalism' simply require a robust application of egalitarian or libertarian principles of justice and rights such that the consequences of group difference and conflict - for example, discrimination and racism - can be dealt with. For others, these familiar forms or arguments are inadequate to face the problems of difference throw up by 'circumstances of multiculturalism'. To respond to these new circumstances, it is argued, we need to rethink our 'categories and values and offer a new form of theoretical language or ideology. (Kelly, 2007: 4).

É nesse sentido, considera Kelly, que o multiculturalismo pode ser tomado como uma nova ideologia (uma teoria política enraizada na prática e na experiência política), o último "ismo" e não somente um modo de se referir ao pluralismo e a diversidade nas sociedades contemporâneas. 
Assim como Hall, Kelly também afirma que não se pode considerar que haja um único multiculturalismo. Avalia a existência de dois núcleos centrais dos argumentos que compõem a teoria do multiculturalismo: a cultura e a igualdade. A partir da posição tomada pelos diferentes autores em referência a esses dois conceitos, se pode compreender o modo como constroem suas teorias.

O tema é rico, complexo e vasto para ser discutido em poucas páginas. Apesar disso, a síntese feita por Kelly é exemplar para auxiliar a entender as diversas posições.

\section{A Cultura}

Quando se trata de cultura, é importante considerar que alguns autores vão defini-la como algo central na construção da identidade, defendendo que a comunidade é mais importante que o indivíduo (ou sua autonomia). Considerados comunitaristas (como Bhikhu Parekh), contrários às teses liberais que proclamam a autonomia e a liberdade dos indivíduos, acreditam que: 1- a cultura do grupo (as comunidades culturais) é parte do contexto no qual as identidades são formadas; 2- sem o grupo não existe o indivíduo; 3- fora do grupo não existe o indivíduo; 4atacar a cultura do grupo é atacar aos indivíduos que pertencem a essa cultura. “... individual identity is shaped by and provide through membership of groups, of which cultural groups are perhaps the most important". (Kelly, 2007: 7).

Já os liberais perfeccionistas (perfectionist liberal) oferecem outro sentido e importância para a cultura mais compatível com os pressupostos da liberdade e da autonomia. Ao contrário de liberais (como John Rawls e Brian Barry) que defendem a neutralidade do Estado no que tange ao modo como qualquer indivíduo decide viver sua vida ou o que considera bom ou o melhor para si mesmo, os liberais perfeccionistas (no dizer de Kelly, como Will Kymlicka) creem que seja fundamental garantir que o Estado (ou outras instâncias) não irá interferir nem no que diz respeito ao direito de cada um viver a sua vida como bem entender nem no direito de que esse "bem viver" seja definido a partir de normas e valores determinados por uma cultura.

Contudo, os perfeccionistas criticam a estreiteza da neutralidade defendida pelos teóricos liberais. "What makes a person's life go well is ultimately that it is something that can be endorsed from the inside by the person whose life it is, and if this is so then person is entitled to have their choices protected from the external coercion of others or of the state". (KELLY, 2007, p. 8).

A cultura desempenha um papel fundamental já que é ela que oferece os valores por meio dos quais se construir e definir o que seria uma vida autônoma.

Culture is this sense is a moral resource, as it provides the lived structure of values, beliefs and obligations that we need in order to make autonomy possible. Without a context of choice there would be nothing from which we could make an autonomous choice about the good life. Autonomy is always 
situated in a thicker ethical life, and this is what is provided by culture (Kelly, 2007: 8).

Cabe aos Estados o respeito às culturas a partir das quais as pessoas definem o que seria o bom ou o mau para suas vidas.

Temos, portanto duas posições em referência ao local e à importância da cultura. Ambas a consideram fundamental, mas enquanto os comunitaristas a colocam antes do indivíduo, da liberdade e da autonomia, os liberais perfeccionistas a veem como o caminho por meio do qual se define a autonomia e a liberdade de todos os indivíduos e grupos. Autores como Parekh questionam até mesmo os conceitos de autonomia e liberdade por seus contornos intrinsecamente demarcados pelo mundo ocidental. Haveria povos e culturais que definiriam sua noção de bem viver sem vínculo com a exigência ocidental de autonomia individual e liberdade (como direito de escolha).

\section{A Igualdade}

Outro aspecto a ser considerado quando se fala em teorias do multiculturalismo é o modo como compreendem e o lugar que dão ao conceito de igualdade. Do lado dos multiculturalistas liberais (ou liberal multiculturalists, novamente tendo como exemplo Kymlicka), não se pode abrir mão da ideia de igualdade em qualquer teoria ou sistema político moralmente aceitável. 0 problema surge quando se pergunta: igualdade de quê? Ou, dito de outra forma, o que deve ser distribuído para que todos tenham igualdade, direitos, tratamento e respeito? Essa é a questão.

0 debate, nesse caso, é travado de maneira intensa entre os autores do liberal-igualitarismo.

Álvaro De Vita oferece os contornos dessa discussão pelo ponto de vista do liberal igualitarismo. Para o autor, o liberal igualitarismo é:

a posição normativa segundo a qual uma sociedade democrática justa é aquela comprometida com a garantia de direitos básicos iguais e uma parcela equitativa dos recursos sociais escassos - renda, riqueza e oportunidades educacionais e ocupacionais - a todos os seus cidadãos. A ideia central desse ideal normativo se apoia em uma divisão moral de trabalho entre a sociedade e seus membros individuais. À sociedade - aos cidadãos como um corpo coletivo cabe a responsabilidade de dar forma a uma estrutura institucional que propicie aqueles direitos e oportunidades para todos, "sem distinção de qualquer tipo, tais como raça, etnia, sexo ou religião" (para fazer uso da frase que quase invariavelmente aparece nos artigos iniciais das declarações de direitos); aos cidadãos individualmente, cabe decidir que uso farão em suas vidas desses recursos institucionalmente garantidos. (Vita, 2002: s/p).

Essa posição política normativa se assentaria nas teses da justiça distributiva, segundo a qual existem três tipos de bens que são relevantes. De Vita nos informa que esses bens são: 1bens que são passíveis de distribuição (renda, riqueza, acesso a oportunidades educacionais); 2bens que não podem ser distribuídos diretamente, mas que são afetados pela distribuição dos 
primeiros (conhecimento e autorrespeito); 3- bens que não podem ser afetados pela distribuição de outros bens (capacidades físicas e mentais). Os liberais igualitaristas, inspirados, pela obra de John Rawls (2002), afirmam que a justiça se vincularia aos dois primeiros tipos de bens (os bens primários).

Vita, salienta, ainda, que em uma sociedade liberal justa se deve considerar dois fatores principais:

1. Cada pessoa tem o mesmo direito a um esquema plenamente apropriado de liberdades básicas iguais, desde que seja compatível com a garantia de um esquema idêntico para todos; e 2. As desigualdades sociais e econômicas somente se justificam se duas condições forem satisfeitas: (a) se estiverem vinculadas a posições e cargos abertos a todos em condições de igualdade equitativa de oportunidade; e (b) se forem estabelecidas para o máximo benefício possível dos membros da sociedade que se encontrarem na posição mais desfavorável (princípio de diferença). (Vita, 1999: 41).

O autor associa, a sua explicação, outros argumentos por meio dos quais deixa claro que, em termos liberais igualitários, a liberdade deve ser prioridade e as instituições não podem se fundar em julgamentos sobre o valor das atividades e objetivos nos quais os indivíduos se empenham ou das associações e comunidades das quais façam parte. Deve-se, portanto, garantir as igualdades de oportunidades e a justa distribuição dos bens primários.

Esse é, também, o argumento de Brian Barry (2002), segundo o qual a igualdade de oportunidades pode ser alcançada por meio da distribuição de direitos, liberdades e recursos: o conjunto de oportunidades são constituídas por estes bens primários.

Apesar disso, nas sociedades atuais, segundo Barry haveria grande concentração de renda, ou seja, péssima distribuição, o que viria ocorrendo, cada vez mais acentuadamente, nos grandes centros, fazendo com que os serviços oferecidos a população mais pobre se tornem cada vez piores. $\mathrm{O}$ autor acusa o multiculturalismo de ser cego a estas questões enquanto seus teóricos investem tempo e mais tempo discutindo as mudanças no cânone.

Também argumenta que se o liberalismo é acusado de ser cego às diferenças, isso não pode ser tomado como necessariamente ruim já que a justiça, se pretende que seja cega. Outro aspecto considerado por Barry é que a crítica segundo a qual o liberalismo desejaria erradicar todas as formas tradicionais de vida em nome da autonomia individual não seria verdadeira. 0 que os liberais defendem é a ausência de coerção contra aqueles que não querem seguir à tradição. Para o autor, cultura não seria o tipo de entidade sobre a qual se possa atribuir direitos. 0 que deveria ser objetivo de normatização não seria a cultura em si mesma, mas as pessoas que a portaria.

O que distribuir e o que valorizar como parâmetro para a justiça faz multiplicar os argumentos. Percebe-se que, agora, os termos do debate não se restringem às questões culturais. Os liberais igualitários não partem desse pressuposto. Os aspectos estruturais concernentes aos bens primários são focalizados. Nesse sentido, para os autores do "multiculturalismo" que se ocupam das discussões sobre a diferença posicional, o que importará será considerar em que medida as sociedades cegas às diferenças mantêm e reafirmam a desigualdade no acesso às oportunidades para aqueles que se encontram em posições subalternas, ou mais vulneráveis, em razão de sua diferença.

É nesse terreno que a batalha entre Iris Marion Young e Brian Barry é travada. 
Para Barry, o modo popular de afirmar que o liberalismo não é acolhedor das diferenças é dizer que ele é assimilacionista. Essa afirmação teria sido enfatizada nos ataques ao liberalismo orquestrados, segundo o autor, por Iris Marion Young ao dizer que, para o liberalismo seria desejável que todas as diferenças deixassem de existir.

A preocupação de Young é que, apesar das políticas de igualdade de oportunidades propalada pelos liberais, alguns grupos continuam sem sucessos na obtenção de bens e posições sociais. Deveria haver uma proporcionalidade na distribuição desses bens, por grupos. A autora sugere que o princípio de justiça distributiva deveria ser substituído por políticas da diferença. Neste sentido, as questões de justiça seriam transformadas em questões de reconhecimento de grupo e autodeterminação. Isso significaria que somente quando os grupos oprimidos estivessem proporcionalmente representados se tornaria possível construir normas justas para lidar com as injustiças reais. Só assim as desvantagens seriam, efetivamente, corrigidas por meio da ação política.

Na perspectiva de Kelly, as concepções de Young indicam que se deve levar a igualdade a sério, pensando a igualdade para além do confinamento liberal que somente a associa com a igualdade de oportunidades.

\section{Igualdade de Oportunidades versus Igualdade de Resultados}

A igualdade defendida por Young não se associa ao reconhecimento de culturas, unicamente, mas ao reconhecimento pautado na percepção de que, historicamente, alguns estariam constantemente em situação de desvantagem. Por isso a autora não fala em grupos culturais, e sim em grupos sociais.

Os grupos sociais incluem, mas não se limitam a grupos culturais. Entre os grupos sociais, estariam àqueles baseados em gênero, raça e etnicidades (além de cultura e religião). 0 que os torna um grupo social é que formam suas identidades a partir de práticas comuns de vida, pelo reconhecimento de uma história comum e do mesmo status social. A identidade é construída a partir da partilha de um destino comum.

Um ponto fundamental para entender a noção de grupo social é que sua identificação não é dada pela adoção, consciente, de práticas ou modos de agir, mas sim pelo modo como é visto pelos outros grupos sociais. Se considerarmos o caso de uma raça (a raça negra, por exemplo), a identidade de um indivíduo de cor preta como membro do grupo social "negro" seria fixada pela forma como outros grupos o veriam: sua cor e história comum que determina um status social. Entretanto, isso envolve pouco ou nenhum significado em termos de práticas comuns. Ou seja, não é condicionante que todos os negros tenham a mesma cultura ou religião para serem definidos como "negros", bastando para isso, que sejam vistos como "negros", recebendo, em razão disso, tratamento similar, tendo oportunidades similares de participação política e acesso aos bens e empregos, compartilhando experiências comuns de vida, em virtude disso tudo. Isso, obviamente, não implica a inexistência de uma fonte de identificação a partir do modo como são vistos, já que seriam atribuídas a eles algumas características comuns. 0 fundamental é que 
essas pessoas pertencem ao mesmo grupo social porque partilham experiências comuns estabelecidas pelo modo como interagem com os outros grupos sociais, a partir do lugar que ocupam na sociedade.

Sendo assim, a defesa da proporcionalidade na distribuição das oportunidades de acesso aos bens e posições sociais está intimamente ligada a conhecer, enxergar e reconhecer a história e o status que a sociedade dá a cada grupo social.

Contudo, contra esse argumento, Barry enfatiza que se deve garantir a igualdade de oportunidades como uma solução para as questões de injustiça social. Uma vez baseadas no liberal igualitarismo, então, os resultados são indiferentes para os liberais. Não é parte de sua preocupação que alguns grupos estejam sub-representados em carreiras e na distribuição de oportunidades. De fato, se a liberdade é distribuída como um componente primário do liberal igualitarismo, então, o exercício desta liberdade irá garantir diferentes performances e diferenças nos resultados já que os interesses e as motivações são distribuídos aleatoriamente. Isso diria respeito ao mérito individual.

Por essas e outras razões, Young não assume o paradigma liberal igualitário que implicaria somente em impedir obstáculos no processo de entrada (o começo do processo), considerando que isso seria suficiente para uma sociedade justa. A autora enfatiza que sem que se observe uma igualdade nos resultados (o final do processo) não se pode observar se houve ou não houve opressão do grupo e/ou uma justa distribuição dos bens primários. É preciso verificar se há proporcionalidade dos grupos na distribuição dos recursos. Os resultados iguais oferecem o paramêtro a partir dos quais os pontos de partida devem ser julgados.

Para Young, ainda, a prática da justiça distribuitiva finda por reforçar os equivocos e as falhas no processo de distribuição porque não busca enxergar o que poderia estar oculto nas distribuição das oportunidades, aparentemente, iguais de acesso. Por exemplo, como impedir que o mercado de trabalho lance mão de práticas discriminatórias (baseados em gênero e raça )? O paradigma corretivo distributivo não alcançaria esses fatores.

De Vita, indica discordância em referência a esse argumento. 0 autor alega que, em acordo com os princípios do liberal igualitarismo, uma sociedade justa, deveria evitar formas de desigualdades moralmente arbitrárias, quais sejam, as associadas a fatores como cor, raça, gênero, sexo; fatores ambientais como a fortuna social e a fortuna genética, dissociando os quinhões distributivos das loterias genéticas e impedindo que hajam barreiras definidas pelos fatores adscritivos que dificultem o acesso às oportunidades.

Mas, como evitar que isso ocorra nas sociedades que temos hoje, momento em que não se pode, e não se quer, retornar à posição original imaginária na qual seríamos todos recobertos por um véu que nos impedisse de ver nossas diferenças? Como partir do pressuposto que as diferenças existentes não foram usadas para alicerçar desigualdades e ratificar preconceitos e formas de discriminações que se tornam, aparentemente, perenes?

Por isso, Young afirma que o preconceito pode continuar operando nos regimes de distribuição de direitos e acesso às oportunidades na medida em que reitera expectativas negativas consagradas pela história e pelo modo como "sempre" se lidou e se enxergou alguns grupos sociais.

Mas, os liberais, por princípio, não podem exigir que as pessoas não tenham preconceitos e não respeitem, de modo igual, o modo de vida e as escolhas dos outros. Podem?

O problema, contudo, para Young, não se refere a escolhas livres, nada tem a ver com liberdade ou autonomia já que as escolhas podem ser orientadas por censuras internas que 
respondem a essas expectativas que a sociedade tem em relação aos membros dos grupos sociais. Isso nem de longe seria liberdade ou representaria qualquer modo de autonomia. Seria necessário considerar, além das questões de direitos e de igualdade de oportunidades, como os bens sociais e as oportunidades são constituídas, quais os critérios de acesso a profissões, carreiras, empregos e a todos os outros bens sociais. Verificar como os acessos são estruturados pelos modelos e pelas relações de poder, ter em mente e em conta como as oportunidades estão atreladas às expectativas sociais. Somente se considerando todos esses aspectos se poderia encontrar normas sob as quais consolidar as sociedades democráticas justas.

$O$ ideal seria defender um igualitarismo que unisse igualdade de resultados e igualdade de oportunidades? A resposta de Kelly é sim. Ele constróe seus argumentos em defesa de uma igualdade de status considerando que, se uma diferença no status que os grupos tem na sociedade se mantem de maneira sistemática, então, isso é sinal de discriminação, opressão e dominação. Nesse caso, medidas de inclusão devem ser tomadas para que não se sustente a ideia de que os indivíduos devem ser responsáveis por sua própria sorte.

\section{Diferença Cultural versus Diferença Posicional}

A síntese apresentada por Kelly permite perceber que as discussões sobre multiculturalismo envolvem tanto questões de cultura quanto de igualdade e liberdade. No campo dos culturalistas-comunitaristas, estaria Bhikhu Parekh, do lado dos multiculturalistas liberais, Will Kymlicka e dos defensores da política da diferença, strictu sensu, estaria Iris Marion Young, se considerarmos sua defesa da tese de justiça associada à igualdade de resultados e na distribuição proporcional de bens e posições sociais.

Para mim não é claro é distinto que Iris Marion Young se encontre entre os autores do multiculturalismo. Sua proposta em defesa da proporcionalidade na participação dos grupos se volta para os grupos sociais e não para os grupos culturais. Young, se ocupa com discussões que vão além das questões do multiculturalismo ao envolverem os temas do reconhecimento de status e da paridade participativa.

A autora salienta esse aspecto ao dizer:

It has become a truism that a politics of difference is equivalent to "identity politics," which is about claims of justice concerning cultural difference. In this essay I take issue with this set of equivalences. There are at least two versions of a politics of difference, which I call a politics of positional difference and a politics of cultural difference. They share a critical attitude toward a differenceblind approach to politics and policy. They differ, however, in how they understand the constitution of social groups, and in the issues of justice that they emphasize. While both versions of a politics of difference appear in contemporary political debates, I perceive that over the last two decades both the attention of public discourse and that of political theorists has shifted from 
the politics of positional difference to a politics of cultural difference. I argue that this shift is unfortunate because it tends to obscure important issues of justice and because it tends to limit the framing of difference politics to a liberal paradigm. We should affirm both approaches, I argue, but also be clear on the conceptual and practical differences between them. (Young, 2007: 79).

Young explica que há diferenças entre as vertentes teóricas que consideram a diferença cultural e aquelas que consideram a diferença posicional.

Vimos que a diferença posicional se refere, principalmente, às questões estruturais. Grupos sociais podem sofrer dificuldades para alcançar o bem estar em virtude da forma como as instituições operam, limitando suas oportunidades e não considerando que aspectos como raça, cor, gênero, etnia possam influir na limitaçao dessas oportunidades. Já a diferença cultural se refere a ausência de liberdade para que os membros das comunidades culturais se expressem e pratiquem suas crenças como queiram, partilhem seus valores, eduquem e socializem seus filhos dentro desses valores; os obrigando a buscar uma outra forma de vida por meio da qual consiguam sobreviver: a assimilação.

Para Young, é patente que as diferenças estruturais acabam implicando questões culturais, também. Contudo, voltar-se, exclusivamente, para o aspecto cultural pode resultar que as demandas se destinem somente para o tema da liberdade e obscureçam as questões da desigualdade nas oportunidades estruturadas pela divisão do trabalho, pelas hierarquias nas tomadas de decisão, pelas normas e padrões que as instituições utilizam para organizarem a vida social.

Embora afirme que ambas devem ser consideradas, nota-se uma crítica ao paradigma da política da diferença cultural como algo que tende a não contemplar, integralmente, os efeitos do liberalismo cego às diferenças. Sua ênfase no aspecto posicional/estrutural em muito corresponde à proposta teórica de Nancy Fraser (2007) que considera que, uma concepção normativa moralmente justa, correta e eficiente, nos tempos de hoje, deve ter uma perspectiva multidimensional que contemple: redistribuição (econômica); reconhecimento (cultural); representação (política). Os três tipos de injustiça associados a essas dimensões devem ser sanadas por meio do critério da paridade participativa.

A partir da teoria de Young, se poderia, sem muito esforço, argumentar em prol de qualquer outra forma de ação afirmativa, sem recorrer a argumentos que envolvam a constituição de comunidades culturais.

Contudo, a questão da cultura e o argumento do multiculturalismo (ao contrário dos argumentos associados à igualdade de resultados e às questões estruturais) também são utilizados quando se tratam da implementação de políticas afirmativas (ações afirmativas) para grupos sociais vulneráveis sobretudo quando a vulnerabilidade se associa a raça/cor e gênero. Daí a necessidade de investigar quais seriam os grupos sociais passiveis de terem suas demandas por direitos tratadas por meio de políticas multiculturais.

Penso que uma resposta as essas questões aflorarão após conhecermos um pouco mais os argumentos que nutrem as políticas públicas multiculturais a partir das discussões feitas por dois autores do multiculturalismo já, resumidamente, apresentados acima: Parekh e Kymlicka. 


\section{Parekh: diversidade comunal}

Bhikhu Parekh (2000) alega que, embora existam várias demandas por reconhecimento associadas à diversidade cultural, as demandas por reconhecimento associadas ao multiculturalismo são aquelas que tratam de questões de defesa das identidades entranhadas, fixadas e determinadas por uma cultura tradicional. 0 autor afirma que há várias formas de diversidades culturais na Modernidade, mas o multiculturalismo diria respeito àquilo que define como diversidade comunal.

A diversidade comunal é a que brota e é sustentada por uma pluralidade de comunidades de longa data, cada qual com sua própria história e seu modo de vida, o qual pretende preservar e transmitir. Exemplos: velhos e novos imigrantes; comunidades antigas e estabelecidas desde muito tempo como os judeus, os ciganos, muçulmanos, amish, indígenas que vivem em territórios definidos e concentrados, bascos, catalães, os escoceses, os galeses e os quebequenses (exemplos do autor).

No caso do Brasil, certamente poderiam ser considerados como parte de uma diversidade comunal (além dos grupos mencionados acima residentes no território nacional e os associados às religiões antigas), os quilombolas e outras comunidades tradicionais. 0 fato de ter um modo de vida que se prolonga pelo tempo e que deve ser protegido para que aquela comunidade continue a existir (e sem o qual ela pereceria ou seria assimilada) é essencial no que tange aos direitos defendidos pelo multiculturalismo. E, nesse aspecto, há certa confusão.

Alguns creem que a existência de diversidade cultural associada à discriminação dos grupos minoritários implica, necessariamente, a constituição de uma diversidade comunal que demande políticas públicas multiculturais. Mas, não se pode esquecer que os membros das comunidades culturais só podem ser definidos como o que são (grupos culturais) por pertencerem e viverem sua cultura, sem a qual teriam que ser pensados como outras pessoas, grupos, seres humanos. Essa identidade é interna ao grupo, definida - de dentro para fora - pelos parâmetros que os grupos culturais criaram, em algum momento da história pregressa. Exatamente o oposto do que ocorre com os grupos sociais, cuja definição é gerada a partir de parâmetros estabelecidos externamente ao grupo - de fora para dentro - pela sociedade. É assim, como vimos com Young, a partir dessa definição externa e estrutural (posição social, falta de oportunidades, partilha de experiência comum de vida etc.) que se criam as condições para identificações.

Para evitar essa miscelânea sobre o que pertenceria ou não ao campo do multiculturalismo é que Parekh redefiniu o conceito.

0 autor chama atenção para o fato de que, além da diversidade comunal, legitimamente associada a demandas multiculturais, ainda haveria a diversidade de perspectiva e a diversidade subcultural.

A diversidade subcultural diria respeito aqueles que, apesar de dividirem uma ampla cultura comum, teriam diferentes crenças (que não se limitam a questões religiosas) e práticas que divergiriam do que é definido pela cultura ampla. A partir dessas crenças e práticas, se redefiniriam e definiriam suas vidas.

Para Parekh, estariam nesse grupo da diversidade subcultural os gays, lésbicas, aqueles que seguem estilos de vida ou modelos de famílias não convencionais, trabalhadores de minas, pescadores, executivos transnacionais, artistas e outros. Eles construiriam e buscariam marcar 
espaços dentro do sistema comum de valores para seus estilos de vida. Por isso, não representariam ou teriam uma cultura alternativa, diversa, mas buscariam oferecer pluralidade para a cultura já existente.

A outra forma de diversidade seria a de perspectiva que diria respeito a crítica feita por membros de uma mesma cultura ao modo restritivo que a cultura da qual fazem parte assumiria em relação a alguns de seus membros. Parekh considera que estariam nessa categoria, por exemplo, feministas que questionariam, profundamente, os valores patriarcais; alguns religiosos que questionam a orientação secular da cultura; ambientalistas que criticam o viés antropocêntrico e tecnocrático da cultura. Isso não faria desses e de outros grupos similares representantes de subculturas só por eles questionarem os pilares da cultura existente. Tampouco constituiriam distintas comunidades culturais porque vivem sob os valores da cultura hegemônica e adotam, mesmo com críticas, o seu modo de ver o mundo. Apesar disso, apresentam uma perspectiva nova, intelectual e moral, sobre como essa cultura dominante poder ser reconstituída.

As políticas multiculturais, vimos, se destinam à diversidade comunal, em sociedades multiculturais.

As sociedades podem ser multiculturais (ou seja, composta por uma diversidade de povos e culturas), mas somente ocorre o multiculturalismo (no sentido político e ideológico), quando oferecem uma resposta normativa à diversidade cultural presente nela e que não deseja ser assimilada pela cultura dominante ou faz demandas próprias em nome de sua cultura. Multiculturalismo, então, está associado a uma preocupação normativa, qual seja, estabelecer parâmetros por meio dos quais se possa julgar, avaliar, contemplar e reconhecer a diversidade presente nos estados nacionais.

A definição de Parekh objetiva estabelecer parâmetros por meio dos quais se possam julgar as demandas por direitos de grupos em nome de sua diversidade. 0 autor considera que as sociedades multiculturais trazem problemas que não têm paralelo na história. Elas precisam encontrar maneiras de conciliar as demandas legítimas de unidade e diversidade, conseguir a unidade política, sem uniformidade cultural, sem ser assimilacionista, cultivando entre seus cidadãos um sentimento comum de pertença, respeitando as suas diferenças culturais legítimas e valorizando as identidades culturais plurais, sem enfraquecer o direito de ser cidadão. Para ele, essa seria uma tarefa política imensa e nenhuma sociedade multicultural até agora teria tido sucesso em enfrentá-la. Parte da dificuldade se encontraria exatamente na complexidade de estabelecer o que seria o multiculturalismo e como definir seus limites, em termos normativos.

Parekh afirma que uma sociedade multicultural estável e coesa, vibrante e à vontade com ela mesma deve cumprir determinadas condições que incluem: uma estrutura de autoridade construída consensualmente; um conjunto coletivo e aceitável de direitos constitucionais; um Estado justo e imparcial; uma cultura comum multiculturalmente constituída; uma educação multicultural; uma visão plural e abrangente da identidade nacional. 


\section{Kymlicka: direitos humanos e multiculturalismo}

Kymlicka, oferece uma definição mais ampla para multiculturalismo visto que o pensa dentro de dois escopos principais: o do liberalismo e o dos direitos humanos.

Não haveria uma definição universal aceitável para o multiculturalismo liberal. Como há muitas definições, o multiculturalismo liberal pode ser tomado como a visão segundo a qual os Estados não devem apenas retomar o conjunto familiar comum de direitos civis, políticos, sociais e de cidadania que são protegidos em todas as democracias constitucionais e liberais. Devem adotar, também, vários direitos para grupos específicos ou políticas que visem reconhecer e contemplar as distintas identidades e aspirações dos grupos étnicos, oferecer alguma forma adicional de reconhecimento público ou algum suporte para a acomodação, reconhecimento de grupos étnicos, suas identidades e práticas. Para entender a ideia de uma democracia liberal multicultural, portanto, é necessário primeiro entender os antigos modelos de estados nacionais homogeneos.

Para Kymlicka, raros são os países mono-nacionais: a Islândia, Portugal e Coréa seriam exemplos mais comuns. A ilusão de homogeneidade percebida nos estados nacionais é construída por meio da adoção de várias políticas e táticas políticas tais como: 1 - adoção de uma língua nacional adotada nas burocracias, serviços públicos, forças armadas, educação superior etc; 2- construção de um sistema nacional e compusório de educação que promova um currículo modelo focado em ensinar a língua, literatura e história do grupo dominante; 3 - centralização do poder político, eliminando as formas locais e pré-existentes de soberania e autonomia; 4difusão da língua e da cultura do grupo dominante por meio de instituições nacionais (mídia, museus etc); 5- adoção de símbolos celebrando os heróis da nação que são associados ao grupo dominante e estabelecendo feriados associados a eles, nomes de ruas, prédios e símbolos por meio dos quais possam ser honrados; 6- a construção de um sistema legal e jurídico unificado operando na língua do grupo dominante; usando a tradição legal deste grupo e abolindo os sistemas legais dos grupos minoritários que seriam pré-existentes a formação do estado-nação; 7- adoção de políticas de assentamento que encoraja os membros dos grupos dominantes a residirem em áreas que histórica e tradicionalmente pertenceriam aos grupos dominados ou às minorias; 8- a adoção de políticas de imigração que obrigue os imigrantes a conheceram a língua e a história nacional como condições para ganharem cidadania, dando preferência aos imigrantes que partilham a mesma língua, religião e cultura dos grupos dominantes; 9- a apreensão de terras, florestas, áreas de pesca e reservas minerais que pertenciam, antes, a grupos minoritários e indígenas declarando esses espaços como recursos nacionais a serem utilizados em benefício da nação.

Para se contrapor a essas ações que visam a homogeneização, são defendidas e definidas políticas multiculturais que tenderiam a conciliar a diversidade cultural dentro dos estados nacionais liberais com o modo de vida e as tradições dos povos que residem no local. Então, esse modo de multiculturalismo transformaria e temperaria os estados nacionais liberais.

Exemplos de políticas multiculturais, nesse caso, podem ser: adoção do multiculturalismo nos currículos escolares, ou seja, ensino de conteúdos associados a culturas diferentes da hegemônica; permissão para a dupla cidadania; financiamento de atividades culturais de grupos e etnias por meio de políticas oficiais de incentivo à cultura; extensão de políticas de ações 
afirmativas para grupos de imigrantes em situação de desvantagem; reconhecimento de leis baseadas nos costumes; permissão de educação bilíngue ou instrução na língua materna dos imigrantes; políticas que permitam que imigrantes se tornem residentes permanentes e futuros cidadãos; permissão de práticas religiosas, respeito à religiões e obediência a feriados religiosos; respeito e permissão do uso de vestimentas associadas a costumes e religiões em locais públicos e em escolas públicas.

Para efetivar essas políticas, os estados liberais multiculturais partiriam da negação da premissa de que um estado é uma possessão de um único grupo nacional. Ao contrário, o estado deve ser visto como uma possessão de vários cidadãos com diferentes culturas. Também repudiariam as políticas nacionais que visariam a assimilar e excluir os membros das minorias e dos grupos não dominantes. Em um estado liberal multicultural, os indivíduos teriam acesso a todas as instituições sem serem obrigados a negar sua identidade etnocultural. 0 estado também aceitaria a obrigação de reconhecer e acomodar a história, língua e cultura dos grupos não dominantes e reconheceria a injustiça histórica associada à assimilação, exclusão e discriminação; e manifestaria o desejo de oferecer algum tipo de remédio ou reparação contra isso. Para Kymlicka, essas ideias interligadas são comuns a praticamente todos os esforços pelo multiculturalismo.

Ele considera que o multiculturalismo se aplica, como se pode perceber a estados pluriétnicos e a estados multinacionais.

O multiculturalismo liberal é atribuído a alguns grupos específicos. Essa categoria difere de país para país, mas teria como baliza os mesmos modelos. Os modelos mais comuns são (e nisso há uma concordância com Parekh): a) velhas minorias - old minorities (indigenas e outros grupos históricos que já estavam no território antes dele ter sido tomado por outros povos e antes de se configurar como uma nação moderna ou como um país independente), e b) novas minorias - new minorities (provenientes de outras nações e outras culturas e admitidas em um país como imigrantes/refugiados/asilados após o pais ter conquistado sua independência legal).

Fundamental, para o autor (e nisso ele difere substancialmente de Parekh) é que, o multiculturalismo a ser aplicado nos estados liberais deve ter como limite o respeito aos direitos humanos, em acordo com o que foi definido pelas Nacões Unidas, a partir de 1948.

Enquanto Parekh considera que a definição do que são os direitos humanos teria levado em conta somente os valores ocidentais, desprezando o sentido de humanidade que nasceria em culturas consideradas "outras" ou rest (o resto, na contenda West versus Rest cf. Hall,1992), Kymlicka avalia que o multiculturalismo liberal foi inspirado e constrangido pelos ideais dos direitos humanos e somente pode ser entendido como um novo estágio do gradual esforço pelos direitos humanos.

Kymlicka identifica a sequência de movimentos que teriam sido inspirados nos ideais dos direitos humanos: entre 1948 e 1966, os movimentos pela descolonização explicitado pela Resolução 1514 das Nações Unidas, em 1960. Entre 1955 e 1965 os movimentos pelos direitos civis dos negros nos Estados Unidos. Esse movimento também teria inspirado movimentos dos povos indígenas (que definiam sua retórica como Red Power) em diferentes lugares; os movimentos quebecois (que se autodefiniam como white niggers), os católicos norte irlandeses, os caribenhos residentes na Inglaterra. Neste sentido, a demanda por políticas multiculturais seriam somente a etapa mais recente da luta pela implementação de direitos humanos para todos os povos. 
Os direitos humanos devem servir como limites para as políticas multiculturais à medida que obrigam os grupos etnoculturais a se reportarem à gramática dos direitos humanos, dos direitos civis liberais e do constitucionalismo democrático na adoção de suas práticas e costumes. Por isso, Kymlicka explicita os sentidos do que denominou internal restrictions e external protection como pontos fundamentais para a definição do modo como as políticas multiculturais devem ocorrer nas democracias liberais, para garantir os direitos dos grupos etnoculturais e de seus membros.

We need to distinguish two kinds of claims that an ethnic or national group might make. The first involves the claim of a group against its own members; the second involves the claim of a group against the larger society. Both kinds of claims can be seen as protecting the stability of national or ethnic communities, but they respond to different sources of instability. The first kind of intended to protect the group from the destabilizing impact of internal dissent (e.g. the decision of individual members not to follow traditional practices or customs), whereas the second is intendent to protect the group from the impact of external decisions (e.g. the economic or political decision of the larger society). To distinguish theses two kinds of claims, I will call the first "internal restrictions", and the second "external protections" (Kymlicka, 1995: $35)$.

No caso das restrições internas, seu objetivo seria garantir que indivíduos de um determinado grupo etnocultural não sejam oprimidos por seus próprios membros, mas sobretudo garante que o grupo tenha assegurado modos para lidar com seus próprios conflitos internos. Já as proteções externas impedem a ocorrência de injustiças contra os grupos etnoculturais ou minorias nacionais em função de normas externas assumidas pela sociedade hegemônica e que ignorariam as especificidades dos grupos etnoculturais.

0 autor exemplifica seu estudo a partir de casos canadenses, por meio do qual membros de algumas comunidades poderiam ter seus direitos acomodados na medida em que fossem pensados como pertencentes a grupos específicos (first nation, quebequenses, por exemplo). Para ele, haveria ao menos três formas de direitos específicos para grupos: 1- direito ao autogoverno ou direito à autodeterminação dos povos; 2- direitos poliétnicos ou direito a não assimilação das culturas dominantes, direitos de expressão de sua cultura sem preconceito ou discriminação; 3- direitos de representação especial para aqueles que não se encontram representados nas instituições democráticas (mulheres, minorias, pobres, portadores de deficiências...). Contudo, seria fundamental que as democracias garantissem, além dos direitos do grupo, os direitos individuais de cada cidadão.

\section{Concluindo}

Em resumo, vimos que o multiculturalismo (ou seria melhor dizer multiculturalismos) pode ser pensado como desdobramentos de políticas normativas que focalizam as diferenças (ou políticas da/para a diferença). Essas são opostas as políticas liberais igualitárias que, por 
natureza, ignorariam as diferenças e a existência de comunidades culturais focalizando as demandas e as necessidades dos indivíduos, a partir de parâmetros que possam ser generalizados.

É possível afirmar que o multiculturalismo diz respeito a respostas normativas e implementação de políticas públicas em sociedades multiculturais que desejam acomodar suas comunidades culturais, ou grupos etnoculturais, poliétnicos, minorias nacionais, imigrantes ou sua diversidade comunal. Trata-se de garantir o direito à liberdade para viver a partir de normas socioculturais diversas das hegemônicas. Implica a consideração de identidades culturais para as quais o passado importa à medida em que mostra a construção e a permanência dos valores culturais que as definem. A cultura define práticas, contexto para as práticas e formas comuns de vida; define a língua, os símbolos, as regras por meio das quais são orientados. 0 pertencimento ao grupo implica uma necessária identificação subjetiva com esses valores, além da própria identificação de outros membros do grupo que reconhece seus iguais.

Como vimos, há diferentes formas de multiculturalismo, mas não podemos considerar que a mera constatação da existência de diversidade cultural implique que o país optou por tratar essa diversidade por meio de políticas multiculturais. Alguns países irão implementar mais ou menos políticas multiculturais (COTT, 2006; KYMLICKA, 1995) e, outros simplesmente optarão por enxergar a diversidade cultural como parte de sua constituição/configuração, sem contudo, considerar que devam atender qualquer demanda feita em nome de especificidades atreladas à diversidade comunal.

Já as políticas de reconhecimento e igualitaristas envolvem e vão além dos parâmetros definidos como comunais porque incorporam, também, outros aspectos (raça. cor, gênero, orientação sexual seriam exemplos) que afetam aos grupos sociais os tornando vulneráveis ou vítimas de injustiças que também devem ser corrigidas por meio de respostas normativas sob a forma de políticas públicas que os contemplem. Trata-se de garantir o direito a que todos os grupos sociais tenham tratamento igual e que sejam assegurados que fatores estruturais/posicionais, histórica e socialmente construídos não sejam utilizados para lhes impedir o acesso a bens básicos, serviços e oportunidades; e também não se tornem formas de opressão. Alguns países podem escolher tratar demandas por reconhecimento de direitos a partir dessa ótica. Também poderão ocorrer casos nos quais os grupos sociais demandem direitos vinculados tantos a aspectos associados a suas especificidades como grupos etnoculturais quanto a aspectos estruturais/posicionais que lhes tragam desvantagens.

Sendo assim, é possível observar que há uma gama enorme de possibilidades para o tratamento do tema diversidade/diferença nas sociedades modernas. As respostas serão tão criativas quanto a capacidade dos povos e das nações as pensarem e implementarem.

o quadro abaixo resume algumas das ideias discutidas ao longo do texto. 


\begin{tabular}{|c|c|c|c|c|c|}
\hline AUTORES & $\begin{array}{c}\text { DEFINICACAOO NA } \\
\text { FILOSOFIA POLÍTICA }\end{array}$ & $\begin{array}{l}\text { DIVERSIDADES } \\
\text { FOCALIZADAS }\end{array}$ & \multicolumn{2}{|c|}{$\begin{array}{l}\text { CARACTERIZACĀO POLITICA } \\
\text { NORMATIVA }\end{array}$} & EXPLICAÇÖES \\
\hline \multirow{3}{*}{ 紊 } & \multirow{3}{*}{$\begin{array}{c}\text { POLITICA DA } \\
\text { DIFERENÇA CULTURAL } \\
+ \\
\text { MULTICULTURALISMO }\end{array}$} & \begin{tabular}{|l|} 
Diversidade \\
subcultural \\
(năo éparte do \\
multiculturalimo
\end{tabular} & $\begin{array}{l}\text { Politica de } \\
\text { reconhecimento }\end{array}$ & \multirow{3}{*}{\begin{tabular}{|l|} 
Estados \\
multiculturais \\
baseados no \\
universalismo \\
pluralista e em uma \\
noção dialética de \\
natureza humana \\
\\
Esta estrutura \\
normativa ainda \\
está por vir
\end{tabular}} & \multirow{3}{*}{$\begin{array}{l}\text { - Estrutura de autoridade construída } \\
\text { consensualmente; } \\
\text { - Um conjunto coletivo e aceitável de } \\
\text { direitos constitucionais; } \\
\text { - Estado justo e imparcial; } \\
\text { - Cultura comum multiculturalmente } \\
\text { constituida; } \\
\text { - Educaçăo multicultural; } \\
\text { - Visaáo plural e abrangente da identidade } \\
\text { nacional. }\end{array}$} \\
\hline & & $\begin{array}{l}\text { Diversidade de } \\
\text { perspectiva } \\
\text { (não é parte do } \\
\text { multiculturalimo) }\end{array}$ & $\begin{array}{l}\text { Política de } \\
\text { reconhecimento }\end{array}$ & & \\
\hline & & Diversidade comunal & Multiculturalismo & & \\
\hline \multirow{3}{*}{$\frac{\sqrt{2}}{3}$} & \multirow{3}{*}{$\begin{array}{l}\text { LIBERAL } \\
\text { PERFECCIONISMO } \\
+ \\
\text { MULTICULTURALISMO }\end{array}$} & $\begin{array}{l}\text { Povos indigenas - } \\
\text { velhas minorias }\end{array}$ & \multirow{3}{*}{\begin{tabular}{|l|l}
$\begin{array}{l}\text { Multiculturalismo } \\
\text { liberal }\end{array}$ & \\
\end{tabular}} & \multirow{3}{*}{$\begin{array}{l}\text { Estados liberais } \\
\text { multiculturais e } \\
\text { poliétnicos } \\
\text { baseados na idéia } \\
\text { da acomodaçắo da } \\
\text { diversidade e } \\
\text { inspirados e } \\
\text { delimitados pelos } \\
\text { valores dos direitos } \\
\text { humanos } \\
\text { Esta estrutura } \\
\text { normativa já existe, } \\
\text { mas vez ou outra } \\
\text { retrocede }\end{array}$} & \multirow{3}{*}{ 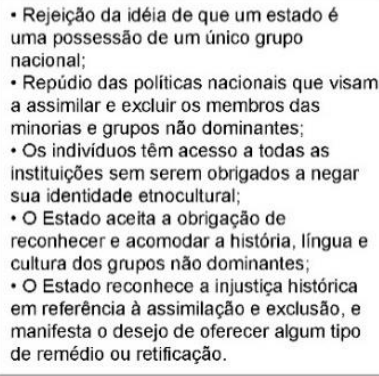 } \\
\hline & & $\begin{array}{l}\text { Minorias nacionais - } \\
\text { velhas minorias }\end{array}$ & & & \\
\hline & & $\begin{array}{l}\text { Imigrantes - } \\
\text { novas minorias }\end{array}$ & & & \\
\hline$\frac{\widehat{c}}{\frac{\alpha}{\alpha}}$ & $\begin{array}{l}\text { LIBERAL } \\
\text { IGUALITARISMO }\end{array}$ & $\begin{array}{l}\text { Não focaliza } \\
\text { diversidades culturais } \\
\text { "os grupos podem } \\
\text { sofrer de privação } \\
\text { material, falta de } \\
\text { oportunidades } \\
\text { iguais e discriminação } \\
\text { e não há nenhuma } \\
\text { razão para supor } \\
\text { que essas } \\
\text { desvantagens derivem } \\
\text { da possessão de uma } \\
\text { cultura diferenciada, } \\
\text { mesmo quando eles a } \\
\text { têm (o que muitas } \\
\text { vezes não é o caso)" } \\
\text { (Barry) }\end{array}$ & $\begin{array}{l}\text { Liberal } \\
\text { igualitarismo }\end{array}$ & $\begin{array}{l}\text { Estados } \\
\text { republicanos, } \\
\text { democráticos e } \\
\text { liberais que adotam } \\
\text { a politica liberal } \\
\text { igualitarista } \\
\text { universalista } \\
\text { Dignidade igual } \\
\text { Nacionalidade } \\
\text { civica } \\
\text { Estrutura normativa } \\
\text { existente nos } \\
\text { estados de } \\
\text { bem-estar social }\end{array}$ & 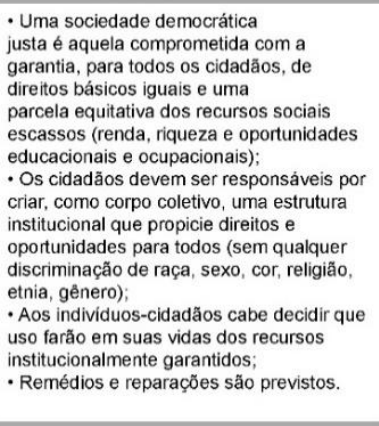 \\
\hline $\begin{array}{l}0 \\
3 \\
\text { ᄋ }\end{array}$ & $\begin{array}{l}\text { POLITICA DA } \\
\text { DIFERENCA } \\
\text { POSICIONAL }\end{array}$ & $\begin{array}{l}\text { Considera a existência } \\
\text { de Grupos sociais }\end{array}$ & \begin{tabular}{|l} 
Politica da \\
Diferença \\
Posicional
\end{tabular} & $\begin{array}{l}\text { Estados } \\
\text { democráticos com } \\
\text { representaçăo } \\
\text { equitativa de todos } \\
\text { os grupos sociais }\end{array}$ & 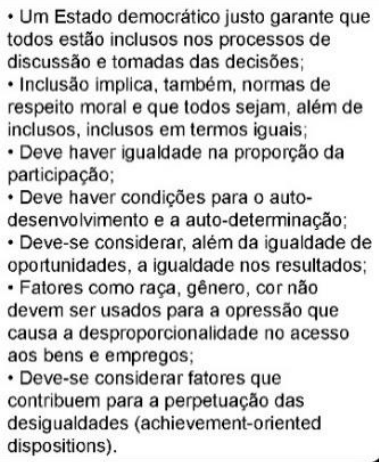 \\
\hline
\end{tabular}

Figura 3 - Posições teóricas em referência à diversidade (Parekh, Kymlicka, Barry e Young) 


\section{Referências Bibliográficas}

Barry, Brian. (2002). Culture \& Equality. Cambridge: Harvard University Press.

Cott, Donna Lee Van. (2006). Multiculturalism versus neoliberalism in Latin America. Em Will Kymlicka., \& Keith Banting. Multiculturalism and the welfare state. (pp. 272-296).0xford: Oxford University Press.

Fraser, Nancy. (2007). Abnormal Justice. Em Günter H. Lenz., \& Antje Dallmann. (orgs). Justice, Governance, Cosmopolitanism, and the Politics of Difference. Reconfigurations in a Transnational World. (pp-117- 147). Berlin: Humboldt-Universität.

Hall, Stuart. (2003). Diáspora. Belo Horizonte: Humanitas.

Hall, Stuart. (1992). The West and the Rest: Discourse and Power. Em Stuart Hall., \& Bram Gieben. (eds.). Formations of Modernity. Understanding Modern Societies an Introduction. (pp. 275-331). Open University/Polity Press.

Hobsbawn, Eric. (1999). Nações e Nacionalismos. São Paulo: Paz e Terra.

Kelly, Paul. (ed.) (2002). Multiculturalism reconsidered. Culture \& equality and its critics. Cambridge: Polity Press.

Kymlicka, Will. (1995). Multicultural Citinzenship. New York: Oxford University Press.

Kymlicka, Will. (2007). Multicultural Odysseys. Oxford: Oxford University Press.

Parekh, Bhikhu. (2000). Rethinking Multiculturalism. Cultural Diversity and Political Theory. Cambridge: Harvard University Press.

Rawls, John. (2002). Uma teoria da justiça. Martins Fontes: São Paulo.

Taylor, Charles. (2000). A política de reconhecimento. In: Argumentos Filosóficos. (pp. 241-274). São Paulo: Loyola.

Taylor, Charles. (2000). Propósitos entrelaçados: o debate liberal-comunitário. Em Argumentos Filosóficos. (pp. 197-220). São Paulo: Loyola.

Vita, Álvaro de. (1999). Uma concepção liberal-igualitária de justiça distributiva. Rev. bras. Ci. Soc., 14(39). Acessado em 12 de novembro de 2019, de: https://doi.org/10.1590/S0102$\underline{69091999000100003}$

Vita, Álvaro de. (2002). Liberalismo igualitário e multiculturalismo. Lua Nova. 55-56, 5-27. Acessado em 12 de novembro de 2019, de: https://doi.org/10.1590/S0102$\underline{64452002000100001}$

Young, Iris Marion. (2007). Structural Injustice and the Politics of Difference. Em Günter H. Lenz., \& Antje Dallmann. (orgs). Justice, Governance, Cosmopolitanism, and the Politics of Difference. Reconfigurations in a Transnational World. (pp- 79-116). Berlin: HumboldtUniversität. 